\title{
An Energy-Saving Output Feedback Control of Single-Rod Electrohydraulic Servo System with Disturbance Observer
}

\author{
Yunfei Wang, Jiyun Zhao $\mathbb{D}$, Haigang Ding $(\mathbb{D}$, and Jiaxiang Man \\ School of Mechatronic Engineering, China University of Mining and Technology, Xuzhou 221116, China \\ Correspondence should be addressed to Jiyun Zhao; zhaojiyun@163.com
}

Received 12 May 2020; Revised 2 June 2020; Accepted 5 June 2020; Published 9 July 2020

Guest Editor: Jing $\mathrm{Na}$

Copyright (C) 2020 Yunfei Wang et al. This is an open access article distributed under the Creative Commons Attribution License, which permits unrestricted use, distribution, and reproduction in any medium, provided the original work is properly cited.

\begin{abstract}
Single-rod electrohydraulic system is widely applied in industrial production due to high power-to-weight ratio, but it generally has a low energy efficiency and has many system states which need to be measured. Therefore, an output feedback controller with energy saving is proposed in this paper. The designed controller only needs a displacement sensor to detect the position of the single-rod cylinder; the other states of the system are estimated by extended state observer (ESO). Besides, a nonlinear disturbance observer (NDO) is introduced to estimate the external mismatched disturbance. The output feedback controller based on extended state observer and nonlinear disturbance observer has a better tracking performance compared with other controllers. In addition, a proportional relief valve (PRV) is introduced to control the supply pressure of the system. The variable supply pressure reduces the energy of throttling loss and overflow loss, which achieves energy saving of about $54 \%$ according to the simulation results. Meanwhile, the tracking error of the energy saving controller is stable at $0.1 \mathrm{~mm}$. In a word, the proposed controller not only achieves energy saving but also has a satisfactory trajectory tracking performance.
\end{abstract}

\section{Introduction}

Electrohydraulic systems are widely used in industrial equipment and mobile applications such as excavator, crane, robot manipulator, and hydraulic press [1-4]. Compared to electric actuators, a hydraulic actuator has advantages of high overload capacity and high power-to-weight ratio but also the disadvantages of poor energy efficiency and low control accuracy [5]. As a result, great attention has been paid to the research on energy-saving control and output control of hydraulic systems in recent years [6-10].

Generally speaking, the low energy efficiency of the electrohydraulic system is due to the fact that the supply energy produced by hydraulic power is much higher than the required energy by the actuators and the excess energy is lost as heat [11]. Therefore, an effective control strategy is to make the supply energy change with the required energy of the actuators to reduce overflow loss and throttle loss. Variable pump can change the supply flow with specific working conditions and be used in hydraulic surface drilling rig for energy-saving control [12]. Speed-variable switched differential pump was introduced into crane boom system to achieve motion tracking and energy saving [2]. A loadsensing pump was utilized to realize position control and improve the energy efficiency in valve-controlled cylinder system $[13,14]$. Besides, frequency converter was applied to change the speed of the electric motor, which can adjust the displacement of constant pump $[15,16]$. The aforementioned variable pump-controlled system usually has the disadvantages of poor response and low control accuracy caused by the big inertias of electric motor and hydraulic pump, though it has the effect of energy saving [17]. Moreover, a variable pump needs large installation space and high configuration cost which brings difficulty to the mobile machinery.

In order to maintain the characteristics of the valvecontrolled system with fast response and high control accuracy, many researchers choose to add a proportional relief valve (PRV) on the original hydraulic system to achieve energy saving. PRV has the ability to adjust the supply pressure, which can reduce the throttle loss of the proportional directional valve (PDV). And the PDV is used to 
improve the position control accuracy of the hydraulic system [18]. An LQR controller and robust controller based on variable supply pressure control were presented to improve the system efficiency in $[11,18]$. A nonlinear backstepping control algorithm was designed in the single-rod system with variable supply pressure for position tracking and energy saving [19]. In [20], a load-prediction method was proposed for a hydraulic actuated robot with variable supply pressure. The proposed load model achieved not only feedforward control on the motion demand but also energy saving on the energy demand. In [21], disturbance observer was introduced to improve tracking performance while achieving energy saving in a hydraulic servo system.

In previous studies, most energy saving control method with variable supply pressure required speed, pressure, and even force sensors of the load for state feedback, but in many cases, only the output of the hydraulic system is measurable. Therefore, it is very meaningful to develop high performance output feedback control strategies [22]. In [23], a high gain observer was designed to estimate the states of double-rod hydraulic system, and a nonlinear output feedback controller based on passivity method was proposed. A nonlinear backstepping control method was presented to realize the position control of single-rod electrohydraulic actuator with a high gain state observer estimating the full states in [10]. And sliding mode control based on high observer was presented to track the desired force in [24] but the external disturbances in the hydraulic system were not considered in high gain observer design. Treating lumped disturbance of the established system model as a new state, extended state observer (ESO) was designed in [25]. Then the ESO was introduced into the electrohydraulic system for full-state observation to achieve high performance output feedback control [26-28]. Besides, unknown dynamics estimator was designed and has been applied in many situations [29-33]. Sliding mode observer [34, 35] and K-filter [36] were also introduced to estimate unmeasured states in hydraulic system.

To further improve the trajectory tracking accuracy of output feedback of the electrohydraulic system, a nonlinear disturbance observer (NDO) was designed to estimate the unknown disturbance [9]. Adaptive robust controller [36] and robust sliding mode controller [37] were presented for output feedback motion control of electrohydraulic system. In [38], RBF neural network was utilized to optimize the parameters in the intelligent controller, while the adaptive mechanism was introduced to the controller to adjust the model parameters of the hydraulic system in $[39,40]$. These proposed control methods have been proved to be successful in improving the position tracking performance of the electrohydraulic system.

In this study, the control purpose of the single-rod electrohydraulic servo system is not only to meet the trajectory tracking accuracy requirement but also to reduce energy consumption as possible. Therefore, the complete hydraulic system is introduced, where variable supply pressure control method is to realize the energy saving based on PRV and output feedback control strategy is to realize high performance position tracking based on PDV. ESO is designed to estimate the full states of the hydraulic system and NDO is presented to compensate for external disturbance and internal inaccurate modelling. Finally, the energy efficiency of the robust backstepping controller in variable supply pressure system is calculated.

The rest of the paper is organized as follows. Section 2 describes the detailed hardware configuration and establishes the math model of the single-rod electrohydraulic servo system. Section 3 introduces the principle of energy saving with variable supply pressure method. The ESO and NDO are designed in Section 4, respectively. The energy saving output feedback controller is introduced in Section 5. Section 6 shows the performance of position tracking and energy saving. A brief conclusion is summarized in Section 7 .

\section{Modelling of Single-Rod Electrohydraulic System}

The configuration for position control and energy-saving control purposes of the proposed system is depicted in Figure 1, which consists of a single-rod actuator, a fixed displacement pump, a displacement sensor, a PDV, and a PRV. The load of the system mainly includes the viscous friction with damping coefficient $b$, the load force $f_{1}$, and the external disturbance force $f_{\mathrm{d}}$. The output $y$ of the system is detected by displacement sensor and is fed back to the controller. The controller uses designed algorithm to calculate the output $u_{1}$ and $u_{2}$. The PDV control signal $u_{1}$ is used to change the actuator flow $Q_{1}$ and $Q_{2}$ to improve position tracking performance, and the PRV control signal output $u_{2}$ is used to change the supply pressure $p_{\mathrm{s}}$ to reduce energy loss.

The dynamics of the single-rod cylinder can be given by Newton's second law:

$$
m \ddot{y}=\left(p_{1} A_{1}-p_{2} A_{2}\right)-b \dot{y}-f_{\mathrm{d}}-f_{1},
$$

where $m$ is the load mass, $p_{1}$ is the pressure in the forward chamber, $p_{2}$ is the pressure in the return chamber, and $A_{1}$ and $A_{2}$ are the ram areas of the forward and return chamber of the asymmetric cylinder, respectively.

The equations of flow into the two chambers flow through the PDV orifices can be written as

$$
\begin{aligned}
& Q_{1}=k_{q} x_{v}\left[s\left(x_{v}\right) \sqrt{p_{\mathrm{s}}-p_{1}}+s\left(-x_{v}\right) \sqrt{p_{1}-p_{\mathrm{r}}}\right], \\
& Q_{2}=k_{q} x_{v}\left[s\left(x_{v}\right) \sqrt{p_{2}-p_{\mathrm{r}}}+s\left(-x_{v}\right) \sqrt{p_{\mathrm{s}}-p_{2}}\right],
\end{aligned}
$$

where $k_{q}$ is the servo valve flow gain coefficient, $x_{v}$ is the spool displacement of PDV, and $p_{\mathrm{s}}$ and $p_{\mathrm{r}}$ are the pump supply pressure and tank pressure of the system. And the function $s(*)$ can be presented as

$$
s(*)= \begin{cases}1, & \text { if } * \geq 0, \\ 0, & \text { if } *<0 .\end{cases}
$$

Due to the fact that the response of the PDV is much faster than the whole system dynamics, the valve dynamic is often neglected without reducing control performance in the 


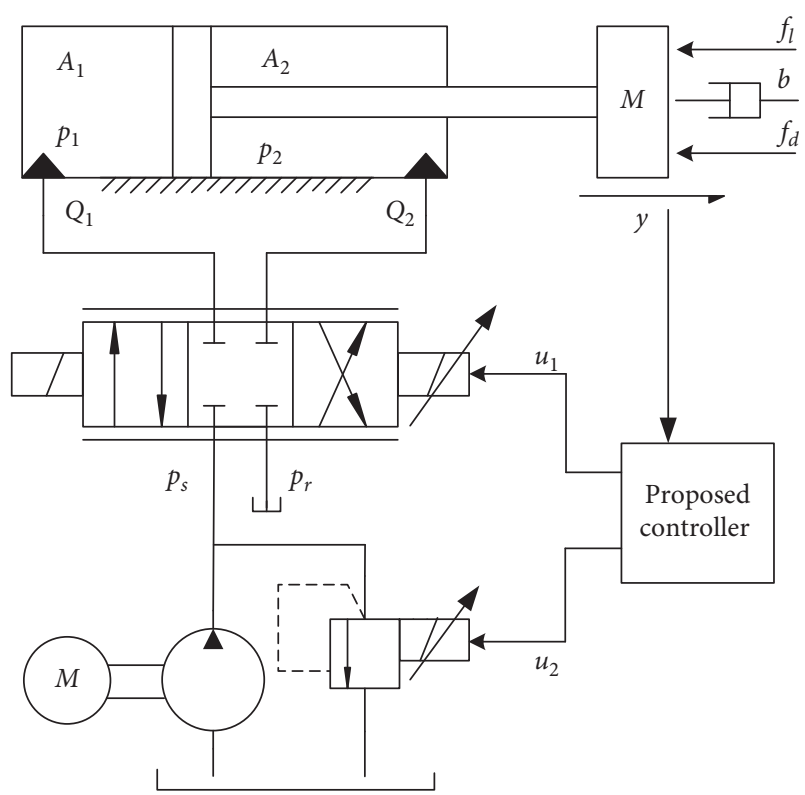

FIGURE 1: Single-rod electrohydraulic servo system.

servo system [5]. Then an approximation between $x_{v}$ and control input voltage $u_{1}$ is described as follows:

$$
x_{v}=k_{s v} \cdot u_{1}
$$

where $k_{s v}$ is voltage gain of PDV spool displacement and is a positive constant.

In general, the pump supplied flow rate is always higher than the actuator required flow rate, and the supply pressure always exceeds the cracking pressure, so the PRV is always open [20]. Besides, the relationship between the control input signal $u_{2}$ of the PRV and the supply pressure $p_{\mathrm{s}}$ is regarded as a linear function:

$$
p_{\mathrm{s}}=k_{r v} u_{2}
$$

where $k_{r v}$ is the pressure gain of $\mathrm{PRV}$ and is a positive constant.

As the current sealing technology is becoming more and more mature, only the internal leakage of the single-rod cylinder is taken into consideration in this paper. In the following, the pressure dynamic equations of asymmetric cylinder are established with the ignorance of the external leakage [41, 42]:

$$
\begin{aligned}
& \dot{p}_{1}=\frac{\beta_{\mathrm{e}}}{V_{01}+A_{1} y}\left[Q_{1}-A_{1} \dot{y}-C_{t}\left(p_{1}-p_{2}\right)\right]+\Delta 1, \\
& \dot{p}_{2}=\frac{\beta_{\mathrm{e}}}{V_{02}-A_{2} y}\left[-Q_{2}+A_{2} \dot{y}+C_{t}\left(p_{1}-p_{2}\right)\right]+\Delta 2,
\end{aligned}
$$

where $\beta_{\mathrm{e}}$ is the effective hydraulic fluid bulk modulus, $V_{01}$ and $V_{02}$ are the initial control volumes of the two chambers, respectively, $C_{t}$ is the internal leakage coefficient of the single-rod cylinder, and $\Delta 1$ and $\Delta 2$ are the modelling errors.

In order to highlight the importance of system supply pressure $p_{\mathrm{s}}$, the load pressure $p_{\mathrm{L}}$ is defined as

$$
p_{\mathrm{L}}=\frac{p_{1} A_{1}-p_{2} A_{2}}{A_{1}}=p_{1}-n p_{2},
$$

where $n$ is the area ratio of the asymmetric cylinder and $n=\left(A_{2} / A_{1}\right)$.

Therefore, the pressure of the actuator chambers can be rewritten as

$$
\begin{aligned}
& p_{1}=\frac{n p_{\mathrm{s}}+p_{\mathrm{L}}}{1+n}, \\
& p_{2}=\frac{p_{\mathrm{s}}-p_{\mathrm{L}}}{1+n} .
\end{aligned}
$$

To facilitate subsequent controller design, the state variables are defined as follows:

$$
X=\left[x_{1}, x_{2}, x_{3}\right]^{T}=\left[y, \dot{y}, \frac{A_{1} p_{\mathrm{L}}}{m}\right]^{T} .
$$

The state space equations of the whole system can be established through (1)-(8). One has

$$
\begin{aligned}
& \dot{x}_{1}=x_{2}, \\
& \dot{x}_{2}=-\frac{b}{m} x_{2}+x_{3}+d_{1}, \\
& \dot{x}_{3}=g_{1} u_{1}-g_{2} x_{2}-\frac{2 m g_{3}}{(1+n) A_{1}} x_{3}-\frac{(n-1) p_{s} g_{3}}{(1+n) A_{1}}+d_{2},
\end{aligned}
$$

where the detailed parameters are shown as follows:

$$
\left\{\begin{array}{l}
k_{t}=k_{q} k_{s v}, \\
d_{1}=\frac{-f_{\mathrm{d}}-f_{1}}{m}, \\
d_{2}=\frac{A_{1} \Delta_{1}-A_{2} \Delta 2}{m}, \\
R\left(u_{1}, x_{3}\right)=s\left(u_{1}\right) \sqrt{\frac{p_{\mathrm{s}}-p_{\mathrm{L}}}{1+n}+s\left(-u_{1}\right) \sqrt{\frac{n p_{\mathrm{s}}+p_{\mathrm{L}}}{1+n}}} \\
g_{1}\left(x_{1}, x_{3}\right)=\frac{k_{t} \beta_{\mathrm{e}} R}{m}\left(\frac{A_{1}}{V_{01}+A_{1} y}+\frac{A_{2}}{V_{02}-A_{2} y}\right), \\
g_{2}\left(x_{1}\right)=\frac{\beta_{\mathrm{e}}}{m}\left(\frac{A_{1}^{2}}{V_{01}+A_{1} y}+\frac{A_{2}^{2}}{V_{02}-A_{2} y}\right) \\
g_{3}\left(x_{1}\right)=\frac{\beta_{\mathrm{e}} C_{t}}{m}\left(\frac{A_{1}}{V_{01}+A_{1} y}+\frac{A_{2}}{V_{02}-A_{2} y}\right) .
\end{array}\right.
$$

In (9), $d_{1}$ is regarded as lump force disturbance which includes external disturbance, load force, unknown structures, and variable modelling parameters and $\dot{d}_{1}$ is bounded by $\dot{d}_{1 \max }$, while $d_{2}$ is regarded as flow disturbance and modelling errors. Besides, $\left|p_{\mathrm{L}}\right|$ is smaller than $p_{\mathrm{s}}$, since $p_{1}$ and $p_{2}$ are both bounded by $p_{\mathrm{s}}$ and $p_{\mathrm{r}}$ in practical hydraulic systems. 


\section{Principle of Energy Saving}

In order to improve energy efficiency of the system, the supply pressure of the pump should be equal to the instantaneous pressure required by the actuator. The minimum required supply pressure is used to drive the single-rod cylinder to complete the trajectory tracking, while excessive supply pressure generates large energy consumption through PDV. And the bigger opening of the PDV results in less throttle loss which means energy efficiency is improved [6]. In addition, the excessive supply flow is drained into the tank with much lower pressure which also results in lower energy consumption in the system.

To track the desired trajectory $y_{\mathrm{d}}$, the actuator pressures $p_{1}$ and $p_{2}$ should satisfy the force equation:

$$
m \ddot{y}_{\mathrm{d}}=p_{1} A_{1}-p_{2} A_{2}-b \dot{y}_{\mathrm{d}}+\widehat{d}_{1} .
$$

If the single-rod cylinder moves forward $\left(\dot{y}_{\mathrm{d}} \geq 0, u_{1} \geq 0\right)$, the desired flow rate $Q_{2 \mathrm{~d}}$ can be calculated according to the orifice flow equations [5]:

$$
Q_{2 \mathrm{~d}}=A_{2} \dot{y}_{\mathrm{d}}=k_{t} \bar{u}_{1} \sqrt{p_{2 \mathrm{~d}}-p_{\mathrm{r}}},
$$

where $\overline{u_{1}}$ is the average input signal of the PDV which affects the performance of trajectory tracking and energy saving, $p_{2 \mathrm{~d}}$ is the desired pressure of the actuator outlet, and $p_{\mathrm{r}}$ is the oil tank pressure. Thus, the desired pressure $p_{1 \mathrm{~d}}$ and $p_{2 \mathrm{~d}}$ of the single-rod cylinder can be expressed as follows:

$$
\begin{aligned}
& p_{2 \mathrm{~d}}=\frac{A_{2}^{2} \dot{y}_{\mathrm{d}}^{2}}{k_{t}^{2} \bar{u}_{1}^{2}}+p_{\mathrm{r}}, \\
& p_{1 \mathrm{~d}}=\frac{1}{A_{1}}\left[\left(\frac{A_{2}^{2} \dot{y}_{\mathrm{d}}^{2}}{k_{t}^{2} \bar{u}_{1}^{2}}+p_{\mathrm{r}}\right) A_{2}+m \ddot{y}_{\mathrm{d}}+b \dot{y}_{\mathrm{d}}-\widehat{d}_{1}\right] .
\end{aligned}
$$

The relationship between the ideal supply pressure $p_{\text {sd }}$ and the forward chamber desired pressure $p_{1 \mathrm{~d}}$ can be described as

$$
A_{1} \dot{y}_{\mathrm{d}}=k_{t} \bar{u}_{1} \sqrt{p_{\text {sd }}-p_{1 \mathrm{~d}}} .
$$

Therefore, the required supply pressure $p_{\text {sd }}$ can be evaluated as follows:

$$
p_{\mathrm{sd}}=\frac{1}{A_{1}}\left[\left(\frac{A_{2}^{2} \dot{y}_{\mathrm{d}}^{2}}{k_{t}^{2} \bar{u}_{1}^{2}}+p_{\mathrm{r}}\right) A_{2}+m \ddot{y}_{\mathrm{d}}+b \dot{y}_{\mathrm{d}}-\widehat{d}_{1}\right]+\frac{A_{1}^{2} \dot{y}_{\mathrm{d}}^{2}}{k_{t}^{2} \bar{u}_{1}^{2}}+p_{m},
$$

where $p_{m}$ is added to the value of desired supply pressure to suppress the effects of unknown disturbance and is set as 10 bar. In this study, $\overline{u_{1}}=0.5 u_{1 \max }$ and $p_{\mathrm{r}}=0$. Similar to the forward movement, the desired supply pressure $p_{s d}$ of the single-rod cylinder during the backward movement $\left(\dot{y}_{\mathrm{d}}<0, u_{1}<0\right)$ can be expressed as

$$
p_{\mathrm{sd}}=\frac{1}{A_{2}}\left[\left(\frac{A_{1}^{2} \dot{y}_{\mathrm{d}}^{2}}{k_{t}^{2} \bar{u}_{1}^{2}}+p_{\mathrm{r}}\right) A_{1}-m \ddot{y}_{\mathrm{d}}-b \dot{y}_{\mathrm{d}}+\widehat{d}_{1}\right]+\frac{A_{2}^{2} \dot{y}_{\mathrm{d}}^{2}}{k_{t}^{2} \bar{u}_{1}^{2}}+p_{m} .
$$

In (16) and (17), it is clear that the desired pressure $p_{s d}$ mainly depends on the system parameters and $\widehat{d}_{1}$ can be observed by state observer, which makes desired supply pressure $p_{\text {sd }}$ to be calculated in real time and improves energy efficiency.

\section{Extended State Observer and Nonlinear Disturbance Observer Design}

To observe the unmeasured system states, the integrated disturbance $d_{2}$ is extended as an additional state $x_{4}$. So the state variables of the system are expanded as

$$
X=\left[x_{1}, x_{2}, x_{3}, x_{4}\right]^{T}=\left[y, \dot{y}, \frac{A_{1} p_{\mathrm{L}}}{m}, d_{2}\right]^{T} .
$$

Then the original system in (9) and (10) can be rewritten as

$$
\begin{aligned}
& \dot{x}=A x+\Phi(x)+G(u, x)+D(t), \\
& y=C x,
\end{aligned}
$$

where the detailed parameters are shown as follows:

$$
\begin{aligned}
& A=\left[\begin{array}{llll}
0 & 1 & 0 & 0 \\
0 & 0 & 1 & 0 \\
0 & 0 & 0 & 1 \\
0 & 0 & 0 & 0
\end{array}\right], \\
& \Phi(x)=\left[\begin{array}{c}
0 \\
\varphi_{1}(x) \\
\varphi_{2}(x) \\
0
\end{array}\right], \\
& G\left(u_{1}, x\right)=\left[\begin{array}{c}
0 \\
0 \\
g_{1}(x) \\
0
\end{array}\right] \text {, } \\
& D(t)=\left[\begin{array}{l}
0 \\
d_{1} \\
0 \\
d_{2}
\end{array}\right], \\
& C=\left[\begin{array}{l}
1 \\
0 \\
0 \\
0
\end{array}\right] \text {, } \\
& \varphi_{1}(x)=-\frac{b}{m} x_{2} \\
& \varphi_{2}(x)=-g_{2} x_{2}-\frac{2 m g_{3}}{(1+n) A_{1}} x_{3}-\frac{(n-1) p_{s} g_{3}}{(1+n) A_{1}}
\end{aligned}
$$

The estimate of $x_{i}$ is defined as $\widehat{x}_{i}$, and the estimate errors are defined as $\tilde{x}_{i}=x_{i}-\hat{x}_{i}$, where $i=1,2,3,4$. Besides, the estimate error of $d_{1}$ is defined as $\widetilde{d}_{1}=d_{1}-\widehat{d}_{1}$. According to the extended system model [37], the ESO is constructed as 


$$
\begin{aligned}
& \dot{\hat{x}}_{1}=\widehat{x}_{2}+\frac{\alpha_{1}}{\varepsilon}\left(x_{1}-\widehat{x}_{1}\right), \\
& \dot{\hat{x}}_{2}=\widehat{x}_{3}+\varphi_{1}(\widehat{x})+\widehat{d}_{1}+\frac{\alpha_{2}}{\varepsilon^{2}}\left(x_{1}-\widehat{x}_{1}\right), \\
& \dot{\hat{x}}_{3}=\widehat{x}_{4}+\widehat{g}_{1} u++\varphi_{2}(\widehat{x})+\frac{\alpha_{3}}{\varepsilon^{3}}\left(x_{1}-\widehat{x}_{1}\right), \\
& \dot{\hat{x}}_{4}=\frac{\alpha_{4}}{\varepsilon^{4}}\left(x_{1}-\widehat{x}_{1}\right),
\end{aligned}
$$

where $\varepsilon>0$ and $\alpha_{i}(i=1,2,3,4)$ is a positive constant.

In order to complete the design of ESO, $d_{1}$ needs to be observed in real time, so NDO is designed as

$$
\dot{\hat{d}}_{1}=\frac{1}{\lambda}\left(\dot{x}_{2}+\frac{b}{m} x_{2}-x_{3}-\hat{d}_{1}\right)
$$

where $(1 / \lambda)$ is the observer gain. To simplify the calculation, an auxiliary state variable is introduced:

$$
\zeta=\widehat{d}_{1}-\frac{x_{2}}{\lambda} \text {. }
$$

Combining (22) and (23), the dynamics of the auxiliary state variable can be written as

$$
\dot{\zeta}=-\frac{1}{\lambda}\left(\zeta+\frac{x_{2}}{\lambda}\right)+\frac{1}{\lambda}\left(\frac{b}{m} x_{2}-x_{3}\right)
$$

Define the estimate error of the auxiliary variable as $\widetilde{\varsigma}=\varsigma-\widehat{\varsigma}$; then the estimation of $d_{1}$ can be got by

$$
\widehat{d}_{1}=\widehat{\zeta}+\frac{\widehat{x}_{2}}{\lambda}
$$

Therefore, the mismatched disturbances can be estimated by NDO in real time, which further improves the observation performance of ESO. Then define an auxiliary variable for ESO as $\eta=\left[\eta_{1}, \eta_{2}, \eta_{3}, \eta_{4}\right]^{T}$, and the auxiliary variable can be further arranged as

$$
\begin{aligned}
& \eta_{1}=\frac{x_{1}-\widehat{x}_{1}}{\varepsilon^{3}}, \\
& \eta_{2}=\frac{x_{1}-\widehat{x}_{1}}{\varepsilon^{2}}, \\
& \eta_{3}=\frac{x_{1}-\widehat{x}_{1}}{\varepsilon}, \\
& \eta_{4}=d_{2}-\widehat{x}_{4} .
\end{aligned}
$$

The dynamics of the auxiliary variable can be transformed as follows:

$$
\begin{aligned}
& \varepsilon \dot{\eta}_{1}=-\alpha_{1} \eta_{1}+\eta_{2}, \\
& \varepsilon \dot{\eta}_{2}=-\alpha_{2} \eta_{1}+\eta_{3}+\frac{1}{\varepsilon}\left(\varphi_{1}(x)-\varphi_{1}(\widehat{x})\right)+\frac{1}{\varepsilon}\left(d_{1}-\widehat{d}_{1}\right), \\
& \varepsilon \dot{\eta}_{3}=-\alpha_{3} \eta_{1}+\eta_{4}+\left(g_{1}(x)-g_{1}(\widehat{x})\right) u_{1}+\left(\varphi_{2}(x)-\varphi_{2}(\widehat{x})\right), \\
& \varepsilon \dot{\eta}_{4}=-\alpha_{4} \eta_{1}+\varepsilon d_{2} .
\end{aligned}
$$

Define the parameter estimate error as $\widetilde{\varphi}_{1}=\varphi_{1}(x)-$ $\varphi_{1}(\widehat{x})$ and $\widetilde{\varphi}_{2}=\varphi_{2}(x)-\varphi_{2}(\widehat{x})$. Referring to (23), the observation errors of the system state can be expressed as

$$
\varepsilon \dot{\eta}=\bar{A} \eta+\frac{1}{\varepsilon} B_{1}\left(\widetilde{\varphi}_{1}+\widetilde{d}_{1}\right)+B_{2} \widetilde{\varphi}_{2}+\varepsilon B_{3} d_{2}
$$

where the parameters can be further expressed as

$$
\begin{aligned}
& \bar{A}=\left[\begin{array}{llll}
-\alpha_{1} & 1 & 0 & 0 \\
-\alpha_{2} & 0 & 1 & 0 \\
-\alpha_{3} & 0 & 0 & 1 \\
-\alpha_{4} & 0 & 0 & 0
\end{array}\right], \\
& B_{1}=\left[\begin{array}{l}
0 \\
1 \\
0 \\
0
\end{array}\right], \\
& B_{2}=\left[\begin{array}{l}
0 \\
0 \\
1 \\
0
\end{array}\right], \\
& B_{3}=\left[\begin{array}{l}
0 \\
0 \\
0 \\
1
\end{array}\right] .
\end{aligned}
$$

The characteristic equation of $\bar{A}$ is described as

$$
|s I-\bar{A}|=\left[\begin{array}{cccc}
s+\alpha_{1} & -1 & 0 & 0 \\
\alpha_{2} & s & -1 & 0 \\
\alpha_{3} & 0 & s & -1 \\
\alpha_{4} & 0 & 0 & s
\end{array}\right]=0,
$$

in which $\bar{A}$ is Hurwitz by choosing the value of $\alpha_{i}(i=1,2,3,4)$, so there exists a positive definite matrix $P$ which can make any given symmetric positive definite matrix $Q$ satisfy the following equation:

$$
\bar{A} T P+P \bar{A}=-2 Q \text {. }
$$

To test the stability of ESO and NDO, a Lyapunov function is defined as

$$
V_{0}=\frac{1}{2} \varepsilon \eta^{T} P \eta+\frac{1}{2} \tilde{d}_{1}^{2} .
$$

The time derivative of $V_{0}$ can be written as

$$
\begin{aligned}
\dot{V}_{0}= & \frac{1}{2} \eta^{T}(\bar{A} T P+P \bar{A}) \eta+\frac{1}{\varepsilon} \eta^{T} P B_{1}\left(\widetilde{\varphi}_{1}+\widetilde{d}_{1}\right) \\
& +\eta^{T} P B_{2} \widetilde{\varphi}_{2}+\varepsilon \eta^{T} P B_{3} d_{2}+\frac{1}{\lambda} \widetilde{d}_{1}^{2}+\widetilde{d}_{1} \dot{d}_{1} \\
\leq & -\eta^{T} Q \eta+\frac{1}{\varepsilon}\|\eta\|\left\|P B_{1}\right\|\left(\left|\widetilde{\varphi}_{1}\right|+\left|\widetilde{d}_{1}\right|\right)+\|\eta\|\left\|P B_{2}\right\|\left|\widetilde{\varphi}_{2}\right| \\
& +\varepsilon\|\eta\|\left\|P B_{3}\right\|\left|d_{2}\right|+\left(\frac{1}{\lambda}+\frac{1}{2}\right) \tilde{d}_{1}^{2}+\frac{1}{2} \dot{d}_{1}^{2} \leq-2 a V_{0}+\delta,
\end{aligned}
$$


where

$$
\begin{aligned}
a= & \min \left\{s_{\min }(Q),-\frac{1}{\lambda}-\frac{1}{2}\right\}, \\
\delta= & \frac{1}{\varepsilon}\|\eta\|\left\|P B_{1}\right\|\left(\left|\widetilde{\varphi}_{1}\right|+\left|\widetilde{d}_{1}\right|\right)+\|\eta\|\left\|P B_{2}\right\|\left|\widetilde{\varphi}_{2}\right| \\
& +\varepsilon\|\eta\|\left\|P B_{3}\right\|\left|d_{2}\right|+\frac{1}{2} \dot{d}_{1 \max }^{2} .
\end{aligned}
$$

The solution of (33) can be expressed as

$$
V_{0} \leq V_{0}(0) e^{-2 a t}+\frac{\delta}{2 a}\left(1-e^{-2 a t}\right)
$$

From (35), it is obvious that $V_{0} \leq \mu$, when $t \longrightarrow \infty$, and the value of $\mu$ depends on the value of $(\delta / 2 a)$. According to Lasalle's invariance principle and (33), if $a \geq(\delta / 2 \mu)$ is taken, $\dot{V}_{0} \leq 0$ is obtained, which proves the system is asymptotically stable.

\section{Output Feedback Controller Design}

In order to achieve precise position tracking while ensuring that the single-rod system has a high energy efficiency, a recursive backstepping controller is proposed and the closed-loop stability of the controller is analysed by Lyapunov technique. The overall control scheme is shown in Figure 2.

The state errors $e_{i}(i=1,2,3)$ are defined as

$$
\begin{aligned}
& e_{1}=x_{1}-y_{\mathrm{d}}, \\
& e_{2}=x_{2}-\beta_{1}, \\
& e_{3}=x_{3}-\beta_{2},
\end{aligned}
$$

where $\beta_{1}$ and $\beta_{2}$ are the virtual control input for $x_{2}$ and $x_{3}$, respectively.

Step 1. Define $\alpha_{1}=\dot{y}_{\mathrm{d}}-k_{1} e_{1}$; then the state error can be rewritten as

$$
e_{2}=x_{2}-\beta_{1}=x_{2}-\dot{y}_{\mathrm{d}}+k_{1} e_{1} .
$$

Since $x_{2}$ is an unmeasurable state, the state error $e_{2}$ cannot be directly calculated. So $e_{2}$ has to be divided into a computable part $e_{2 c}$ and an incalculable part $e_{2 i}$ based on the ESO. And only the calculable part $e_{2 c}$ can be directly used in the output feedback controller design:

$$
\begin{aligned}
e_{2} & =e_{2 c}+e_{2 i}, \\
e_{2 c} & =\hat{x}_{2}-\beta_{1}, \\
e_{2 i} & =\tilde{x}_{2} .
\end{aligned}
$$

Step 2. In accordance with (9), (36), and (37), the dynamic of $e_{2}$ can be described as

$$
\dot{e}_{2}=e_{3}+\beta_{2}-\frac{b}{m} x_{2}+d_{1}-\ddot{y}_{\mathrm{d}}+k_{1} x_{2}-k_{1} \dot{y}_{\mathrm{d}} \text {. }
$$
follows:

$$
\begin{aligned}
& \beta_{2}=\beta_{2 a}+\beta_{2 s}, \\
& \beta_{2 a}=\frac{b}{m} \widehat{x}_{2}-\widehat{d}_{1}+\ddot{y}_{\mathrm{d}}-k_{1} \widehat{x}_{2}+k_{1} \dot{y}_{\mathrm{d}}-e_{1}, \\
& \beta_{2 s}=-k_{2} e_{2},
\end{aligned}
$$

where $\beta_{2 a}$ is the feedforward control law based on the model, $\beta_{2 s}$ is the nominal feedback term, and $k_{2}$ is a positive feedback gain. Substituting the virtual control input $\beta_{2}$ into (39), the dynamic of $e_{2}$ can be rewritten as

$$
\dot{e}_{2}=e_{3}-\frac{b}{m} \tilde{x}_{2}+\tilde{d}_{1}+k_{1} \tilde{x}_{2}-k_{2} e_{2}-e_{1} \text {. }
$$

Step 3. Similar to state error $e_{2}, e_{3}$ is divided into a computable part $e_{3 c}$ and an incalculable part $e_{3 i}$ because of the unmeasured state $x_{3}$ :

$$
\begin{aligned}
e_{3} & =e_{3 c}+e_{3 i}, \\
e_{3 c} & =\hat{x}_{3}-\beta_{2}, \\
e_{3 i} & =\tilde{x}_{3},
\end{aligned}
$$

and the dynamic of $e_{3}$ can be given by

$$
\begin{aligned}
\dot{e}_{3}= & g_{1} u_{1}-g_{2} x_{2}-\frac{2 m g_{3}}{(1+n) A_{1}} x_{3}-\frac{(n-1) p_{s} g_{3}}{(1+n) A_{1}} \\
& +d_{2}-\dot{\beta}_{2 c}-\dot{\beta}_{2 i},
\end{aligned}
$$

where

$$
\begin{aligned}
\alpha \dot{\beta}_{2 c} & =\frac{\partial \beta_{2}}{\partial t}+\frac{\partial \beta_{2}}{\partial x_{1}} \widehat{x}_{2}+\frac{\partial \beta_{2}}{\partial \widehat{x}_{2}} \dot{\hat{x}}_{2}+\frac{\partial \beta_{2}}{\partial \widehat{d}_{1}} \dot{\vec{d}}_{1} \\
\dot{\beta}_{2 i} & =\frac{\partial \beta_{2}}{\partial x_{1}} \widetilde{x}_{2} .
\end{aligned}
$$

$\beta_{2 c}$ is the calculable part which can be directly applied in the output feedback controller design and $\beta_{2 i}$ is the incalculable term. Therefore, the actual control input $u_{1}$ of PDV can be given as

$$
\begin{aligned}
& u_{1}=\frac{1}{\widehat{g}_{1}}\left(u_{1 a}+u_{1 s}\right) \\
& u_{1 a}=g_{2} \widehat{x}_{2}+\frac{2 m g_{3}}{(1+n) A_{1}} \widehat{x}_{3}+\frac{(n-1) p_{s} g_{3}}{(1+n) A_{1}}-\widehat{d}_{2}+\dot{\beta}_{2 c}-e_{2} \\
& u_{1 s}=-k_{3} e_{3}
\end{aligned}
$$

where $u_{1 a}$ is the model compensation term based on ESO and NDO, $u_{1 s}$ is the nominal feedback term, and $k_{3}$ is a positive feedback gain.

Substituting the actual control input $u_{1}$ into (43), the dynamic of $e_{3}$ can be shown as

$$
\dot{e}_{3}=\tilde{g}_{1} u_{1}-g_{2} \tilde{x}_{2}-\frac{2 m g_{3}}{(1+n) A_{1}} \tilde{x}_{3}+\tilde{x}_{4}-k_{3} e_{3}-e_{2} .
$$




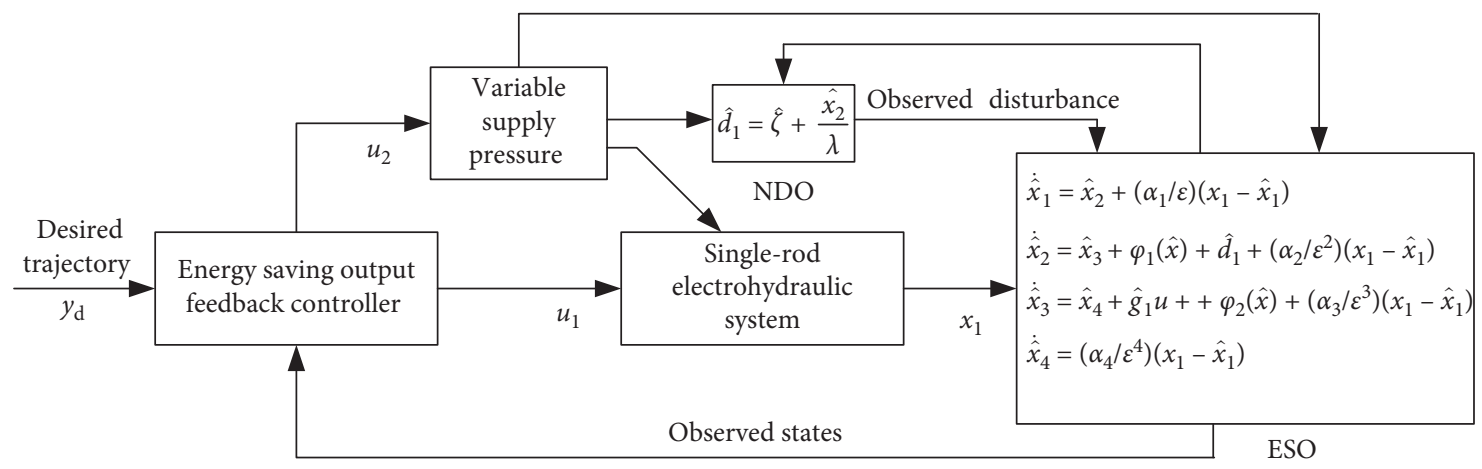

Figure 2: The block diagram of control scheme.

In order to verify the stability of the proposed controller based on ESO and NDO in the single-rod electrohydraulic system, a positive definite function $V$ is defined as follows:

$$
V=\frac{1}{2} e_{1}^{2}+\frac{1}{2} e_{2}^{2}+\frac{1}{2} e_{3}^{2}+V_{0}
$$

Combining (33), (41), (46), and (47), the derivative of $V$ can be described as

$$
\begin{aligned}
\dot{V}= & e_{1} \dot{e}_{1}+e_{2} \dot{e}_{2}+e_{3} \dot{e}_{3}+\dot{V}_{0} \\
\leq & -k_{1} e_{1}^{2}-\left(\frac{k_{2}}{2}-\frac{1}{2}-\frac{b}{2 m}\right) e_{2}^{2}-\left(k_{3}-\frac{u_{1 \max }}{2}-\frac{g_{2}}{2}-\frac{m g_{3}}{(1+n) A_{1}}-\frac{1}{2}\right) e_{3}^{2} \\
& +\left(\frac{1}{\lambda}+1\right) \tilde{d}_{1}^{2}-\eta^{T} Q \eta+\left(\frac{k_{2}}{2}-\frac{b}{2 m}+\frac{g_{2}}{2}\right) \widetilde{x}_{2}^{2}+\frac{m g_{3}}{(1+n) A_{1}} \widetilde{x}_{3}^{2}+\frac{1}{2} \widetilde{x}_{4}^{2} \\
& +\frac{u_{1 \max }}{2} \widetilde{g}_{1}^{2}+\frac{1}{2} \dot{d}_{1 \max }^{2}+\frac{1}{\varepsilon}\|\eta\|\left\|P B_{1}\right\|\left(\left|\widetilde{\varphi}_{1}\right|+\left|\widetilde{d}_{1}\right|\right)+\|\eta\|\left\|P B_{2}\right\|\left|\widetilde{\varphi}_{2}\right|+\varepsilon\|\eta\|\left\|P B_{3}\right\|\left|d_{2}\right| . \\
& \quad V \leq V(0) e^{-2 v t}+\frac{\gamma}{2 v}\left(1-e^{-2 v t}\right),
\end{aligned}
$$

According to (48), the Lyapunov function $V$ is bounded by

where

$$
\begin{aligned}
& v=\min \left\{s_{\min }(Q), k_{1}, \frac{k_{2}}{2}-\frac{1}{2}-\frac{b}{2 m}, k_{3}-\frac{u_{1 \max }}{2}-\frac{g_{2}}{2}-\frac{m g_{3}}{(1+n) A_{1}}-\frac{1}{2},-\frac{1}{\lambda}-1\right\}, \\
& \gamma=\frac{u_{1 \max }}{2} \widetilde{g}_{1}^{2}+\frac{1}{2} \dot{d}_{1 \max }^{2}+\frac{1}{\varepsilon}\|\eta\|\left\|P B_{1}\right\|\left(\left|\widetilde{\varphi}_{1}\right|+\left|\widetilde{d}_{1}\right|\right)+\|\eta\||| P B_{2}\left\|\left|\widetilde{\varphi}_{2}\right|+\varepsilon\right\| \eta\|\| P B_{3} \|\left|d_{2}\right| .
\end{aligned}
$$

According to Lasalle's invariance principle, there will be $V \leq \mu$, when $t \longrightarrow \infty$. Besides, the value of $\mu$ depends on the value of $(\gamma / 2 v)$. Therefore, if the $v \geq(\gamma / 2 \mu)$ is taken, $\dot{V} \leq 0$ is obtained; in other words, the proposed controller of singlerod electrohydraulic system based on ESO and NDO is asymptotically stable.

\section{Simulation Results with Analysis and Discussion}

In order to verify the trajectory tracking effect and energy saving effect of the proposed controller, the entire model of single-rod electrohydraulic system is established and parameters are listed in Table 1 . Besides, $d_{1}=2 \sin (\pi t)$ and $d_{2}=5.0868 \sin (t)$ are introduced to simulate the disturbance and modelling errors of the system. Then PID controller, sliding mode controller (SMC), output feedback controller (OFC), output feedback disturbance observerbased controller (OFDC), and output feedback disturbance observer-based with energy saving controller (OFDESC) are designed and compared. The control parameters of these controllers are displayed in Table 2. The parameters of ESO are set as $\varepsilon=0.01, \alpha_{1}=40, \alpha_{2}=600, \alpha_{3}=4000$, $\alpha_{4}=10000$. 
TABLE 1: Single-rod electrohydraulic system parameters.

\begin{tabular}{|c|c|c|c|}
\hline Parameters & Description & Value & Units \\
\hline$\overline{A_{1}}$ & Effective area of the piston chamber & $1.9625 \times 10^{-3}$ & $\mathrm{~m}^{2}$ \\
\hline $\mathrm{A}_{2}$ & Effective area of the rod chamber & $9.4514 \times 10^{-4}$ & $\mathrm{~m}^{2}$ \\
\hline$P_{\mathrm{s}}$ & Supply pressure & $5 \times 10^{6}$ & $\mathrm{~Pa}$ \\
\hline$P_{\mathrm{r}}$ & Tank pressure & 0 & $\mathrm{~Pa}$ \\
\hline$V_{01}$ & Initial volumes of piston chamber & $3.9 \times 10^{-4}$ & $\mathrm{~m}^{-3}$ \\
\hline$V_{02}$ & Initial volumes of rod chamber & $1.9 \times 10^{-4}$ & $\mathrm{~m}^{-3}$ \\
\hline$\beta_{\mathrm{e}}$ & Effective hydraulic fluid bulk modulus & $10^{9}$ & $\mathrm{~Pa}$ \\
\hline$C_{t}$ & Total leakage coefficient of chambers & $9.2 \times 10^{-13}$ & $\mathrm{~m}^{5} /(\mathrm{N} \cdot \mathrm{s})$ \\
\hline$m$ & Equivalent mass of the load & 80 & $\mathrm{~kg}$ \\
\hline$b$ & Damping coefficient & 3000 & $\mathrm{~N} \cdot \mathrm{s} / \mathrm{m}$ \\
\hline$k_{s v}$ & Voltage flow gain of PDV & $7.245 \times 10^{-8}$ & $\mathrm{~m}^{3} /\left(\mathrm{V} \cdot \mathrm{s} \cdot \mathrm{Pa}^{1 / 2}\right)$ \\
\hline$k_{r v}$ & Pressure gain of PRV & 2.1 & $\mathrm{MPa} / \mathrm{V}$ \\
\hline
\end{tabular}

TABle 2: Contrast controller parameters.

\begin{tabular}{lc}
\hline Controllers & Parameters \\
\hline PID & $k_{P}=1400, k_{I}=500, k_{D}=0$ \\
SMC & $k_{1}=500, c_{1}=900, c_{2}=60$ \\
OFC & $k_{1}=150, k_{2}=500, k_{3}=300$ \\
OFDC & $k_{1}=150, k_{2}=500, k_{3}=300, \lambda=0.002$ \\
OFDESC & $k_{1}=150, k_{2}=500, k_{3}=300, \lambda=0.002, \bar{u}_{1}=5$ \\
\hline
\end{tabular}

The motion trajectory is designed as $y_{\mathrm{d}}=0.1 \sin (2 t) \mathrm{m}$ as Figure 3 shows. The tracking errors of PID, SMC, OFC, and OFDC are depicted in Figure 4, respectively. The tracking error of PID is about $2 \mathrm{~mm}$, while the error of SMC gradually stabilized at $0.5 \mathrm{~mm}$, though there is a big error in the beginning. The tracking error of OFC fluctuates around $0.4 \mathrm{~mm}$, and the tracking performance of the OFDC controller with NDO becomes extremely good. The estimated states of the ESO are depicted in Figures 5-8, and the estimated disturbance of the NDO is shown in Figure 9. Compared with the disturbance artificially added to the single-rod hydraulic system, the estimated values of $d_{1}$ and $d_{2}$ are very accurate, which implies that the ESO can accurately observe the state of the system with modelling error, and NDO can accurately estimate the external disturbance of the system. So the proposed controller with ESO and NDO greatly improves the accuracy of trajectory tracking, when only a position signal can be measured in the single-rod electrohydraulic system.

Figure 10 describes the tracking performance of OFDESC comparing to OFDC. The maximum errors of OFDESC and OFDC are both stable at $0.1 \mathrm{~mm}$, though OFDESC has a larger fluctuation which proves the proposed energy-saving controller also has a good tracking performance with variable supply pressure. In addition, to verify the energy-saving efficiency of the designed controller, the pressure of the system is shown in Figure 11. The fixed supply pressure is 50 bar which is the stable supply pressure of OFDC system. Obviously, the variable pressure is far less than 50 bar which means that the throttling loss energy through PDV of OFDESC is smaller than the throttling loss of OFDC. According to (7), (16), (17), and (21), the estimations of $p_{1}$ and $p_{2}$ are calculated and depicted in Figure 11. The comparison of supply energy between OFDC

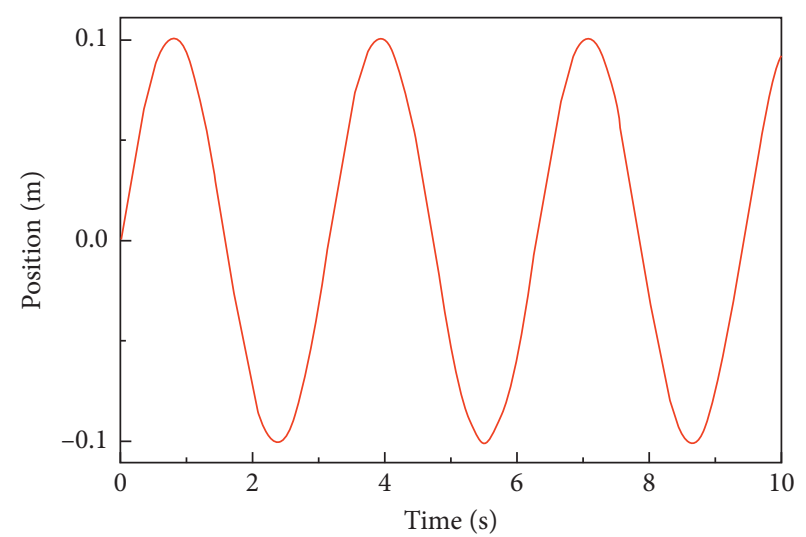

Figure 3: The desired trajectory of the system.

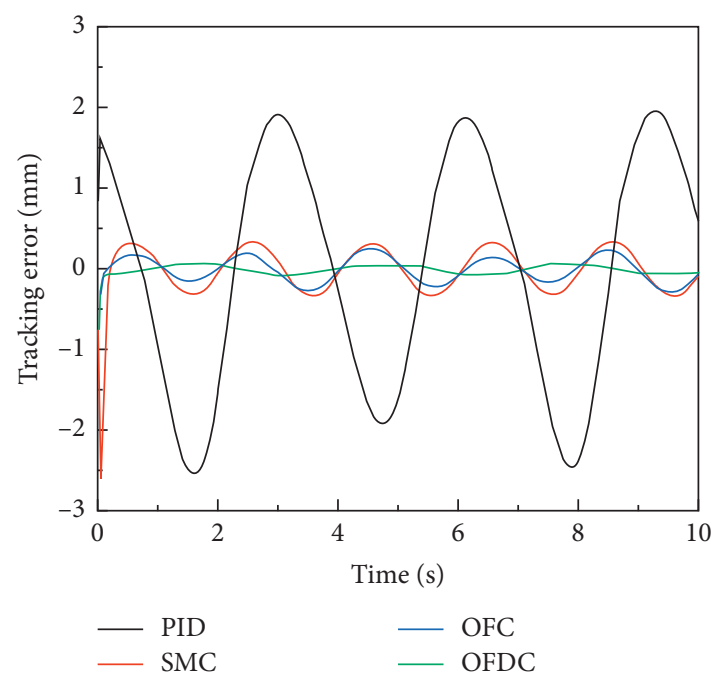

FIgURE 4: Comparison of tracking effect between different controllers.

system and OFDESC system is shown in Figure 12. The flow rate of the pump in the single-rod electrohydraulic system is set as $5 \mathrm{~L} / \mathrm{min}$. Therefore, the energy supply of the OFDC system is $4.17 \mathrm{~kJ}$, while the energy supply of the OFDESC system is $1.9 \mathrm{~kJ}$ in the $10 \mathrm{~s}$ movement. The proposed OFDESC is capable of saving 54\% energy in this desired 


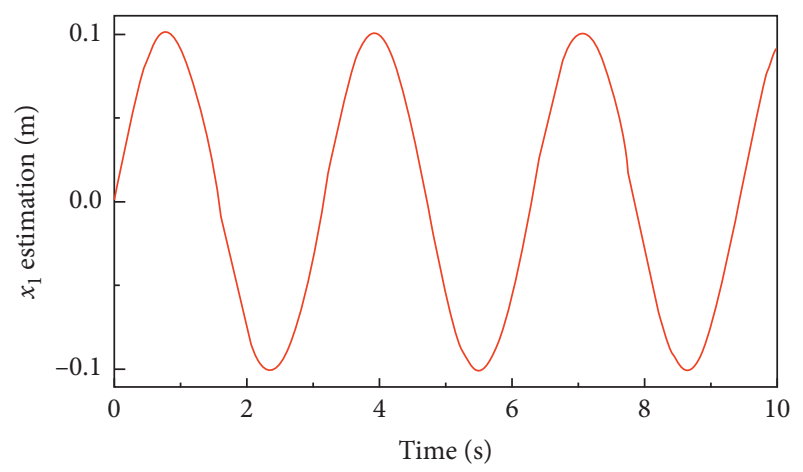

FIgURE 5: $x_{1}$ estimation of ESO for the system.

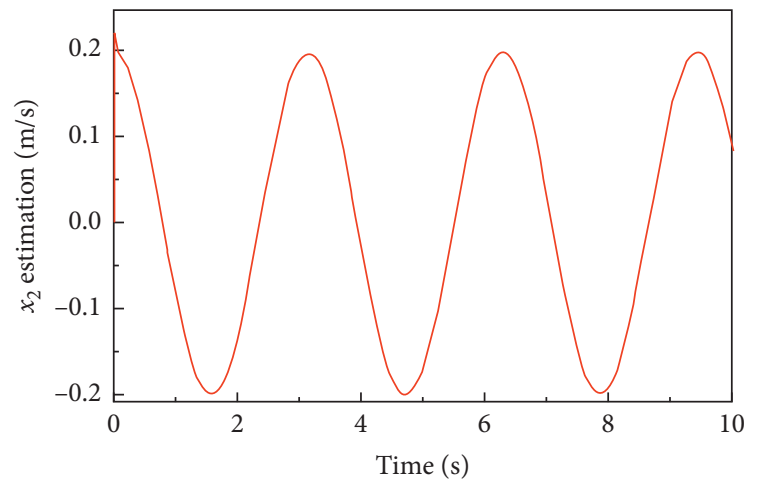

FIgURE 6: $x_{2}$ estimation of ESO for the system.

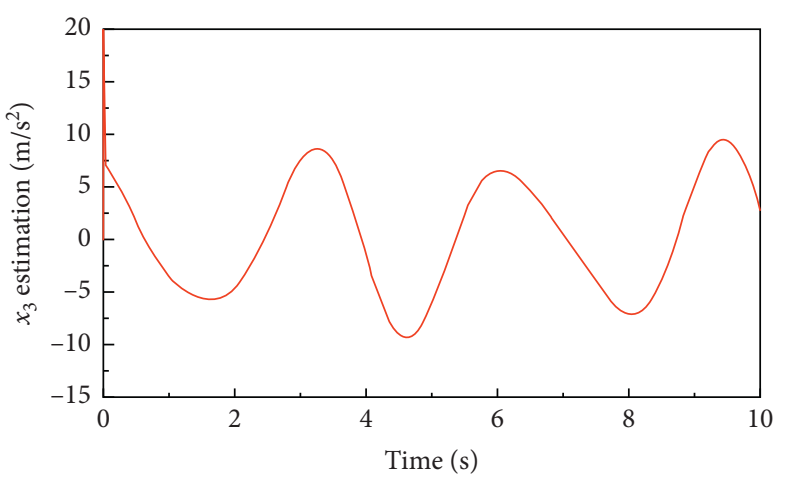

FIgURE 7: $x_{3}$ estimation of ESO for the system.

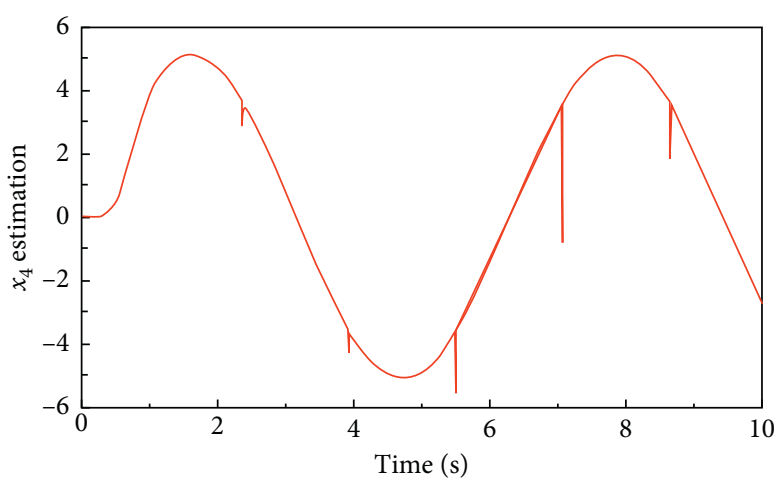

FIgURE 8: $x_{4}$ estimation of ESO for the system.

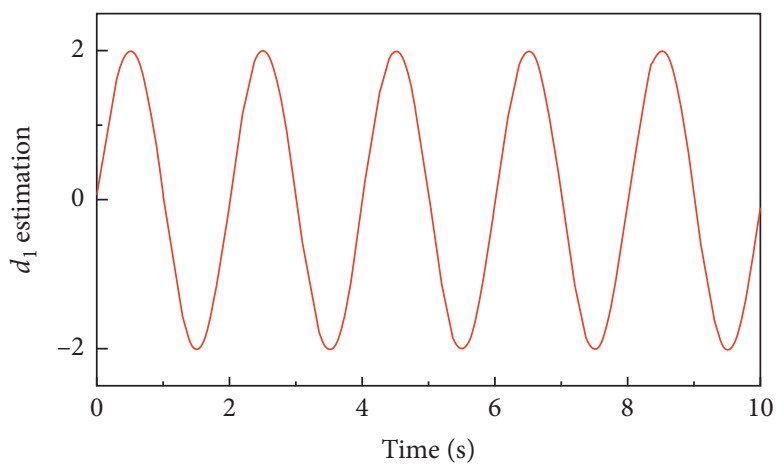

Figure 9: Estimated disturbance of NDO for the system.

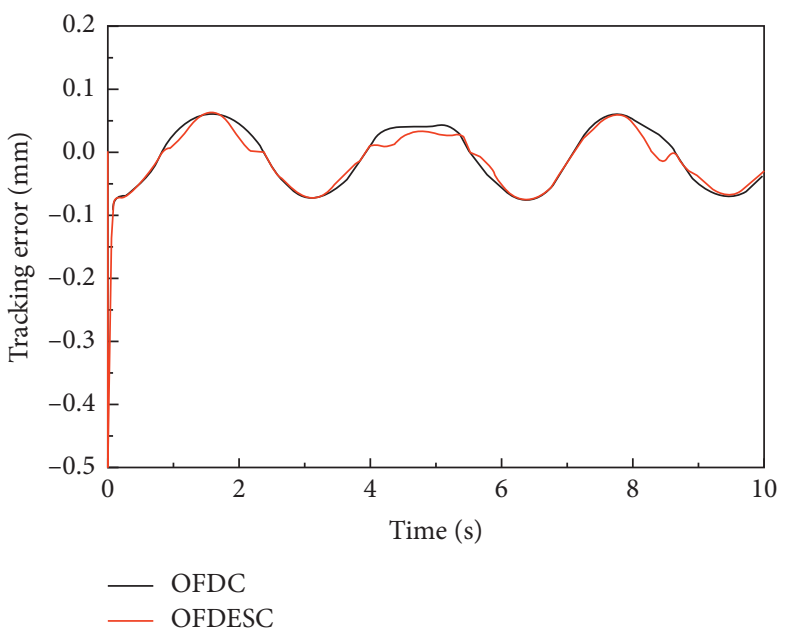

FIgURE 10: Tracking errors of OFDC and OFDESC.

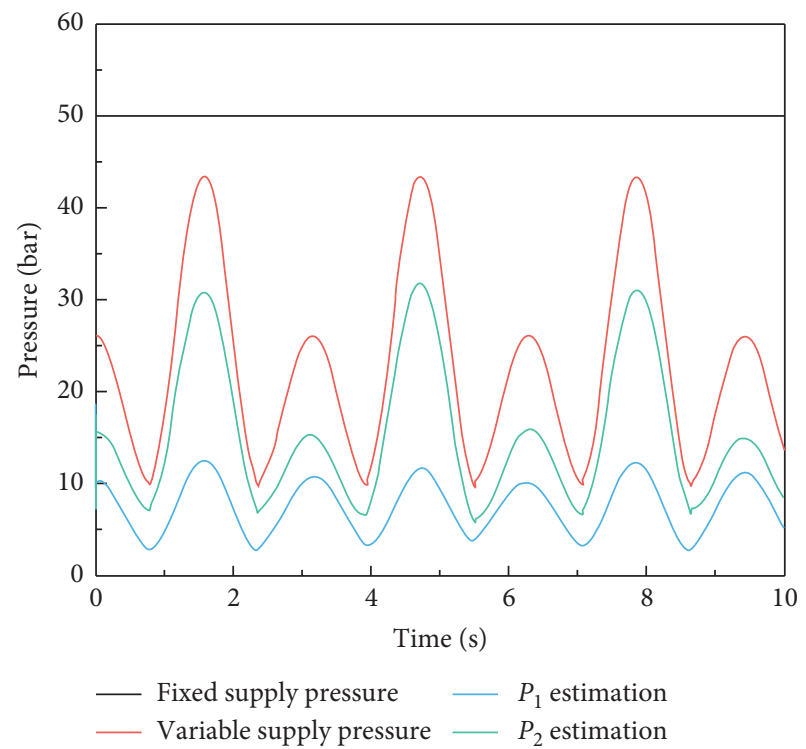

FIGURE 11: Estimated pressures of OFDESC for the system. 


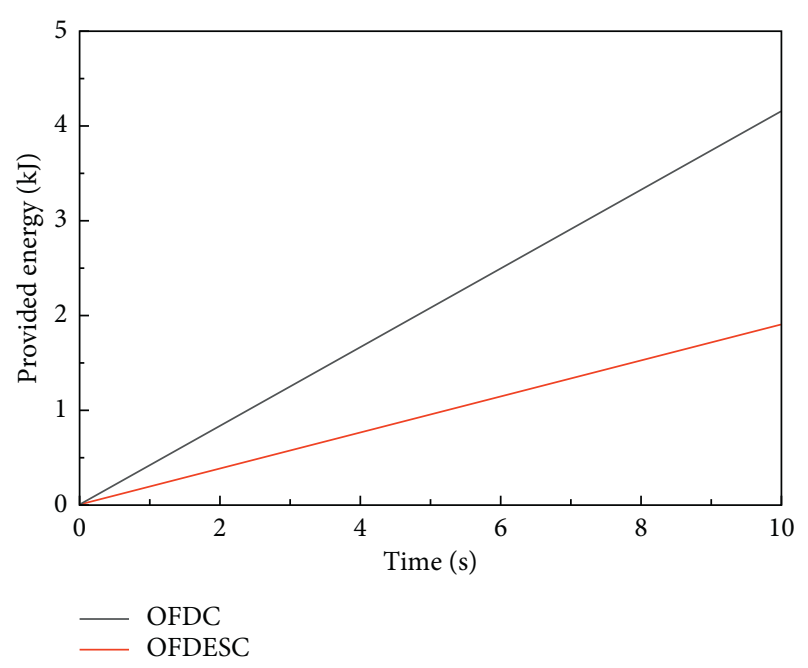

FIGURE 12: Energy provided by the pump of OFDC and OFDESC.

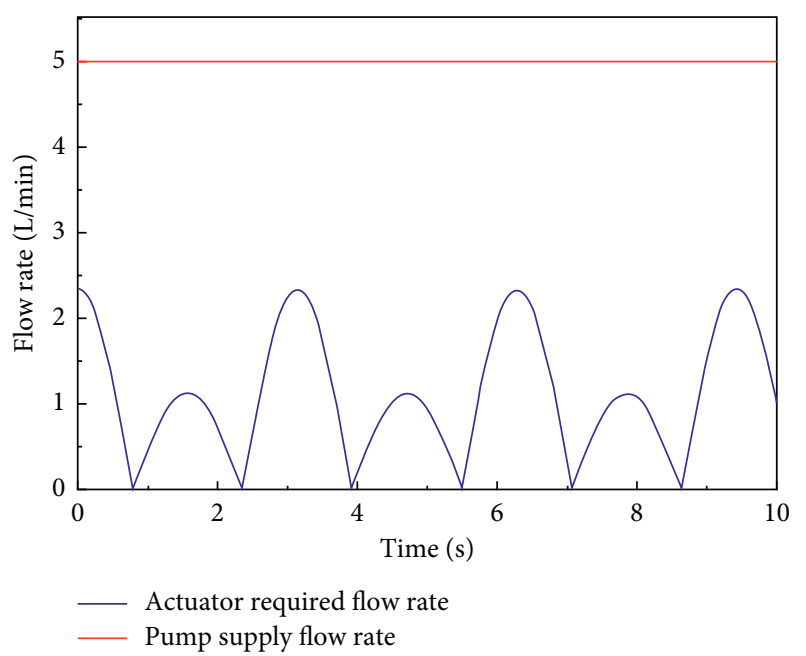

FIgURE 13: Flow rate of the pump and the actuator.

trajectory tracking test with the maximum tracking error of $0.1 \mathrm{~mm}$. In a word, OFDESC achieves energy saving without affecting the trajectory tracking performance comparing with OFDC.

In order to further study the energy utilization of the single-rod electrohydraulic system, the energy of throttling loss and overflow loss is calculated. Figure 13 describes the supply flow rate of the pump and the required flow rate of the single-rod cylinder which is calculated according to (15). In general, the supply flow of the pump is higher than the required flow of the actuator which helps the actuator to do a better trajectory tracking, but excessive supply flow will cause a large overflow loss. In Figure 14, the energy distribution of OFDESC system with a typical harmonic trajectory tracking test is introduced. The supply energy of the pump in OFDC system is $4.17 \mathrm{~kJ}$, while in OFDESC system, it is $1.9 \mathrm{~kJ}$ in the $10 \mathrm{~s}$ movement. The energy of overflow loss of OFDC is $3.2 \mathrm{~kJ}$, while that of OFESC is $1.46 \mathrm{~kJ}$ which is caused by variable pressure controlled by PRV. It is clear that the energy of overflow loss accounts for a large proportion of

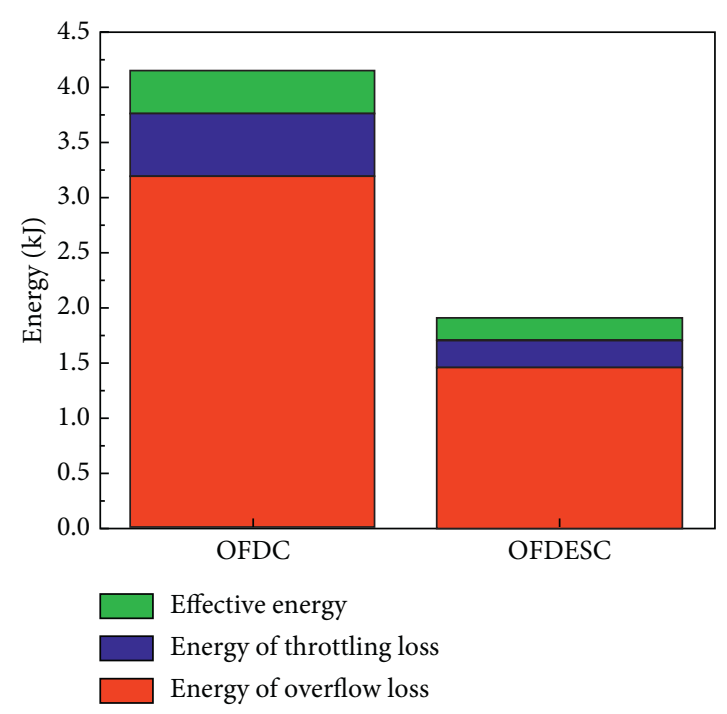

FIGURE 14: Energy distribution of OFDC and OFDESC for the system.

the total supply energy of the system. This is because the flow of the pump should be sufficient to allow the actuator to track any desired trajectory and the overflow will increase, when the expected trajectory is relatively slow. Besides, the energy of throttling loss of OFDESC system is lower than OFDC system. The OFDESC has a $0.25 \mathrm{~kJ}$ throttling loss and OFDC has a $0.56 \mathrm{~kJ}$ throttling loss which proves the effectiveness of the proposed method.

\section{Conclusion}

In this paper, an output feedback controller based on extended state observer and nonlinear disturbance observer with energy saving is proposed. For a single-rod electrohydraulic system with only displacement signal output, the ESO is used to estimate all the states of system and the NDO is used to estimate the external disturbance. The simulation results show that the observers have a satisfactory observation effect in this system. Compared with PID, SMC, and OFC, the proposed controller has a better performance of trajectory tracking with about $0.1 \mathrm{~mm}$ steady-state error. Additionally, the variable supply pressure method controlled by PRV greatly reduces the supply energy. Simulation results show that the supply energy of OFDC is $4.16 \mathrm{~kJ}$, while the supply energy of OFDESC is only $1.91 \mathrm{~kJ}$, whose energy saving of the system is about $54 \%$ with parameters and desired trajectory in this paper. Meanwhile, the tracking performance of OFDESC is as good as OFDC with a stable error of $0.1 \mathrm{~mm}$. So the proposed variable supply pressure method is adaptable, which not only achieves energy saving but also does not affect the trajectory tracking effect. However, it can be found from the energy distribution diagram that the overflow loss energy still accounts for most of the total energy, which is mainly because of the fixed flow rate of the constant pump. The actuator requires different supply flow rate with different expected trajectories, if the desired trajectory is so slow that the more supply flow will be 
directly back to the tank through PRV, which makes the energy of overflow loss increased. Therefore, more research will focus on improving the tracking performance of different desired trajectories, reducing the energy of overflow loss, and further improving energy efficiency. Furthermore, relevant experimental data will be supplemented in future work.

\section{Data Availability}

The data used to support the findings of this study are included within the article.

\section{Conflicts of Interest}

The authors declare that there are no conflicts of interest regarding the publication of this paper.

\section{Acknowledgments}

This work was supported by the National Natural Science Foundation of China (Grants U1910212 and 51675519) and Fundamental Research Funds for the Central Universities (2019XKQYMS37).

\section{References}

[1] L. Ge, L. Quan, Y. Li, X. Zhang, and J. Yang, "A novel hydraulic excavator boom driving system with high efficiency and potential energy regeneration capability," Energy Conversion and Management, vol. 166, pp. 308-317, 2018.

[2] S. r. Ketelsen, L. Schmidt, V. H. Donkov, and T. O. Andersen, "Energy saving potential in knuckle boom cranes using a novel pump controlled cylinder drive," Modeling, Identification and Control: A Norwegian Research Bulletin, vol. 39, no. 2, pp. 73-89, 2018.

[3] H. V. A. Truong, D. T. Tran, X. D. To, K. K. Ahn, and M. Jin, "Adaptive fuzzy backstepping sliding mode control for a 3DOF hydraulic manipulator with nonlinear disturbance observer for large payload variation," Applied Sciences, vol. 9, no. 16, p. 3290, 2019.

[4] H. Huang, X. Zou, L. Li, X. Li, and Z. Liu, "Energy-saving design method for hydraulic press drive system with multi motor-pumps," International Journal of Precision Engineering and Manufacturing-Green Technology, vol. 6, no. 2, pp. 223234, 2019.

[5] M. Jelali and A. Kroll, Hydraulic Servo-Systems: Modelling, Identification and Control, Springer, London, UK, 2003.

[6] P. Ranjan, G. Wrat, M. Bhola, S. K. Mishra, and J. Das, "A novel approach for the energy recovery and position control of a hybrid hydraulic excavator," Isa Transactions, vol. 99, pp. 387-402, 2020.

[7] A. Kumar, K. Dasgupta, and J. Das, "Achieving constant speed of a hydrostatic drive using controlled operation of the pump and enhancing its energy efficiency," ISA Transactions, vol. 90, pp. 189-201, 2019.

[8] M. Jin and Q. Wang, "Energy-saving control for electrohydraulic systems under time-varying negative loads," Proceedings of the Institution of Mechanical Engineers, Part I: Journal of Systems and Control Engineering, vol. 232, no. 5, pp. 608-621, 2018.

[9] G. Yang and J. Yao, "Output feedback control of electrohydraulic servo actuators with matched and mismatched disturbances rejection," Journal of the Franklin Institute, vol. 356, no. 16, pp. 9152-9179, 2019.

[10] Q. Guo, D. Jiang, and T. Yu, "High-gain observer-based output feedback control of single-rod electro-hydraulic actuator," IET Control Theory \& Applications, vol. 9, no. 16, pp. 2395-2404, 2015.

[11] W. Wang and J. Zhao, "Energy-efficient robust control for direct drive and energy recuperation hydraulic servo system," Complexity, vol. 2020, Article ID 6959273, 19 pages, 2020.

[12] X. Liang and W. Wu, "Control strategy of energy saving for power system in hydraulic surface drilling rig," Journal of The Brazilian Society of Mechanical Sciences and Engineering, vol. 40, no. 6, pp. 1-8, 2018.

[13] W. Wang and B. Wang, "An energy-saving control strategy with load sensing for electro-hydraulic servo systems," Strojniški Vestnik-Journal of Mechanical Engineering, vol. 62, no. 12 , pp. 709-716, 2016.

[14] S. H. Cho and P. Noskievič, "Position tracking control with load-sensing for energy-saving valve-controlled cylinder system," Journal of Mechanical Science and Technology, vol. 26, no. 2, pp. 617-625, 2012.

[15] M. Xu, X. Yu, X. Wu, and G. Chen, "State-space modelling and analysis of power assist unit-based variable-speed pumpcontrolled-motor drive system," Journal of the Brazilian Society of Mechanical Sciences and Engineering, vol. 40, no. 1, 2018.

[16] D. Lovrec, M. Kastrevc, and S. Ulaga, "Electro-hydraulic load sensing with a speed-controlled hydraulic supply system on forming-machines," The International Journal of Advanced Manufacturing Technology, vol. 41, no. 11-12, pp. 1066-1075, 2009.

[17] H. Ding, H. Song, J. Zhao, and C. Lin, "Valve-pump parallel variable mode control for complex speed regulation processes," Complexity, vol. 2018, Article ID 8016345, 9 pages, 2018.

[18] A. Tivay, M. Zareinejad, S. M. Rezaei, and K. Baghestan, “A switched energy saving position controller for variablepressure electro-hydraulic servo systems," ISA Transactions, vol. 53, no. 4, pp. 1297-1306, 2014.

[19] K. Baghestan, S. M. Rezaei, H. A. Talebi, and M. Zareinejad, "An energy-saving nonlinear position control strategy for electro-hydraulic servo systems," ISA Transactions, vol. 59, pp. 268-279, 2015.

[20] C. Du, A. R. Plummer, and D. N. Johnston, "Performance analysis of a new energy-efficient variable supply pressure electro-hydraulic motion control method," Control Engineering Practice, vol. 60, pp. 87-98, 2017.

[21] W. Wang and B. Wang, "Disturbance observer-based nonlinear energy-saving control strategy for electro-hydraulic servo systems," Advances in Mechanical Engineering, vol. 9, no. 5, 2017.

[22] J. Yao, Z. Jiao, and D. Ma, "Extended-state-observer-based output feedback nonlinear robust control of hydraulic systems with backstepping," IEEE Transactions on Industrial Electronics, vol. 61, no. 11, pp. 6285-6293, 2014.

[23] W. Kim, D. Won, D. Shin, and C. C. Chung, "Output feedback nonlinear control for electro-hydraulic systems," Mechatronics, vol. 22, no. 6, pp. 766-777, 2012.

[24] G. Xu, N. Lu, and G. Lv, "High-gain observer-based sliding mode force control for the single-rod electrohydraulic servo actuator," IEEE Access, vol. 7, pp. 161849-161857, 2019.

[25] J. Han, "From PID to active disturbance rejection control," IEEE Transactions on Industrial Electronics, vol. 56, no. 3, pp. 900-906, 2009. 
[26] Q. Guo, Y. Zhang, B. G. Celler, and S. W. Su, "Backstepping control of electro-hydraulic system based on extended-stateobserver with plant dynamics largely unknown," IEEE Transactions on Industrial Electronics, vol. 63, no. 11, pp. 6909-6920, 2016.

[27] X. Wang, R. Liao, C. Shi, and S. Wang, "Linear extended state observer-based motion synchronization control for hybrid actuation system of more electric aircraft," Sensors, vol. 17, no. 11, 2017.

[28] C. Luo, J. Yao, and J. Gu, "Extended-state-observer-based output feedback adaptive control of hydraulic system with continuous friction compensation," Journal of the Franklin Institute, vol. 356, no. 15, pp. 8414-8437, 2019.

[29] J. Na, Y. Li, Y. Huang, G. Gao, and Q. Chen, "Output feedback control of uncertain hydraulic servo systems," IEEE Transactions on Industrial Electronics, vol. 67, no. 1, pp. 490-500, 2020.

[30] J. Na, B. Jing, Y. Huang, G. Gao, and C. Zhang, "Unknown system dynamics estimator for motion control of nonlinear robotic systems," IEEE Transactions on Industrial Electronics, vol. 67 , no. 5, pp. 3850-3859, 2020.

[31] J. Na, Y. Huang, X. Wu, S.-F. Su, and G. Li, "Adaptive finitetime fuzzy control of nonlinear active suspension systems with input delay," IEEE Transactions on Cybernetics, vol. 50, no. 6, pp. 2639-2650, 2020.

[32] J. J. E. Slotine and W. Li, Applied Nonlinear Control, Prentice Hall, Trenton, NJ, USA, 1991.

[33] J. Na, S. Wang, Y.-J. Liu, Y. Huang, and X. Ren, "Finite-time convergence adaptive neural network control for nonlinear servo systems," IEEE Transactions on Cybernetics, vol. 50, no. 6, pp. 2568-2579, 2020.

[34] W. Wang, J. Zhao, and H. Ding, "Output feedback nonlinear energy-saving position control of electro-hydraulic asymmetric actuator," Proceedings of the Institution of Mechanical Engineers, Part I: Journal of Systems and Control Engineering, vol. 232, no. 3, pp. 233-243, 2018.

[35] C. Cheng, S. Liu, and H. Wu, "Sliding mode observer-based fractional-order proportional-integral-derivative sliding mode control for electro-hydraulic servo systems," Proceedings of the Institution of Mechanical Engineers, Part C: Journal of Mechanical Engineering Science, vol. 234, no. 10, pp. 1887-1898, 2020.

[36] X. Li, J. Yao, and C. Zhou, "Adaptive robust output-feedback motion control of hydraulic actuators," International Journal of Adaptive Control and Signal Processing, vol. 31, no. 11, pp. 1544-1566, 2017.

[37] W. Shen, H. Huang, and J. Wang, "Robust backstepping sliding mode controller investigation for a port plate position servo system based on an extended states observer," Asian Journal of Control, vol. 21, no. 1, pp. 302-311, 2019.

[38] Z. Liu and T. Chen, "RBF neural network control for linear motor-direct drive actuator based on an extended state observer," Discrete Dynamics in Nature and Society, vol. 2016, Article ID 8390529, 10 pages, 2016.

[39] C. Wang, L. Quan, Z. Jiao, and S. Zhang, "Nonlinear adaptive control of hydraulic system with observing and compensating mismatching uncertainties," IEEE Transactions on Control Systems Technology, vol. 26, no. 3, pp. 927-938, 2018.

[40] Q. Chen, S. Xie, M. Sun, and X. He, "Adaptive nonsingular fixed-time attitude stabilization of uncertain spacecraft," IEEE Transactions on Aerospace and Electronic Systems, vol. 54, no. 6, pp. 2937-2950, 2018.

[41] K. Guo, J. Wei, J. Fang, R. Feng, and X. Wang, "Position tracking control of electro-hydraulic single-rod actuator based on an extended disturbance observer," Mechatronics, vol. 27, pp. 47-56, 2015.

[42] Y. Huang, J. Na, X. Wu, and G. Gao, "Approximation-free control for vehicle active suspensions with hydraulic actuator," IEEE Transactions on Industrial Electronics, vol. 65, no. 9, pp. 7258-7267, 2018. 